August - 2004

\title{
Washington Online Virtual Campus: Infusing culture in dispersed Web-based higher education
}

\author{
Shalin Hai-Jew \\ Seattle University \\ USA
}

\begin{abstract}
Started in 1997, WashingtonOnline Virtual Campus (WAOL) consists of a consortium of 34 community colleges around Washington State to provide asynchronous online learning. WAOL bears many of the features of a loosely coupled organization with its geographically dispersed frontline instructors, fragmented external environment, modularity of courses and supervision, and its use of enhanced leadership and technology to communicate a culture. Recent surveys of its administration, instructors, and staff found disparities in various constituencies' perspectives on the organization's culture, decision-making, values, brand or reputation, communications, and WAOL's authorizing environment. Research suggests that WAOL benefits from some aspects of loose coupling: greater adaptive abilities and responsiveness to the State's college system; "fast" course development and launching; and isolated breakdowns. There is, however, a persistent difficulty in conveying a cohesive culture. There is a perception of WAOL's invisibility among its varied constituencies. This organization is at a crossroads, with the threat of colleges disconnecting from this consortium. WAOL should redefine its direction and purpose, such as coupling with local universities to provide not only associates degrees but full Baccalaureate and/ or Masters degrees. It may strengthen its position by improving learner supports, publicizing its decisions, creating a stronger sense of virtual community among the instructors (as in its recent creation of an online community for instructors), increased participative decision-making and use of line faculty and staff insights, and greater course varieties.
\end{abstract}

Keywords: leadership; culture; organizational culture; consortiums; partnership; disintermediation; virtual organization; loosely coupled organization; distance learning; virtual culture; technology mediation

\section{Introduction}

When public colleges enter the competitive distance learning (DL) environment for the delivery of higher education and training, they enter the market with distinct advantages and disadvantages. The advantages could be their reputation, their insightful knowledge of their respective learners, the brain trust and skills of faculty, and organizational savvy. Yet, because of tight funding issues as non-profit entities, such organizations often need to function in partnerships and consortiums, often in highly politicized environments. Virtual consortiums have the added challenge of creating a cohesive culture across wide geographical distances, among diverse members with unique specializations, in order to function as a unit. As one researcher has 
asked about virtual environments: "How does leadership play itself out in an environment where trust is difficult to build, influence is difficult to express, self-leadership is required, and communication is often ambiguous?” (Zigurs, 2003, p. 342).

\section{Skunkworks to Establishment}

In 1997, Washington State started the Washington State Community andTechnical Colleges ONLINE Consortium to make distance education available. Its mission would be "to facilitate new collaborations among colleges in order to improve the educational system of Washington State for students who would otherwise not have educational opportunities" (History and Mission, 2003, n.p.). WAOL's role has been to increase capacity and access to "anytime anywhere learning through online delivery, support online learners by providing comprehensive online student services, support colleges offering online instruction, and support faculty and staff who serve online learners." Participative decision-making criteria included pragmatic issues: time-to-delivery of courses, costs versus benefits, academic credibility, administrative implementation and flexible improvability.

The U.S. Department of Education released an "Issue Brief" in Feb. 1998 that observed the limited nature of distance learning offerings nationwide: "In Fall 1995, a third of the institutions offered distance education courses, another quarter planned to offer such courses in the next three years, and 42 percent did not offer, and did not plan to offer, such courses in the next three years. A much greater percentage of public than of private institutions offered distance education courses: 58 percent of public two-year and 62 percent of public four-year institutions, compared with two percent of private two-year and 12 percent of private four-year institutions. The percent of institutions offering distance education courses also varied by institutional size and geographic region, with fewer small institutions and fewer institutions in the Northeast offering distance education" (U.S. Department of Education, 1998, p. 1). As for the prevalence of the technologies in use, this report found that only a quarter of the institutions offering distance education courses in Fall 1995 used the Internet; the others used two-way interactive video, one-way pre-recorded video, and other technologies (U.S. Department of Education, 1998).

Foremost among WAOL's achievements has been the institutionalizing of distance education statewide. Broughton, Managing Director of WAOL, says: "WAOL went from a skunkworksnobody-knows-if-it-will-work short-term project, to an institution within the community and technical college system. WAOL was originally under the radar in many ways, which was an advantage in moving quickly. Now it is very visible and has a terrific technical infrastructure that makes it both more efficient and less flexible” (Broughton, 2003c, p. 1).

Today, WashingtonOnline Virtual Campus (WAOL) serves learners who access the combined higher education and certificated offerings of Washington State's 34 community colleges. Thousands of students take college courses through WAOL annually, with over 450 electronic classrooms quarterly. WAOL has trained over 1,000 instructors and has about 350 active instructors at any one time. A range of student services is offered online via the World Wide Web. These include admissions, academic advising, bookstore, career resources, digital library and electronic database access (ProQuest), financial information, learning resources, learning centers, student access and student community. WAOL's website (www.waol.org) has become more informative. Its site map shows the service-oriented approach built on a simple and easy-tonavigate structure. The courseware has changed several times: Embanet's FirstClass, to WebCT, to Intralearn, to the current Blackboard setup. The software has had to meet the requirements of functionality, flexibility, technological stability, ease of operation, and user friendliness. WAOL 
Virtual Campus emphasizes life-cycle cost of technologies and focuses less on first-cost, for responsible asset management. WAOL supports ProQuest database access and the use of Collegis services for addressing student technology problems 24 hours a day, 7 days a week. Nearly US \$1 million has been spent on the development of courses since 1997 (Carlson, 2003, n.p.).

Figure 1: WashingtonOnline Screen Clip

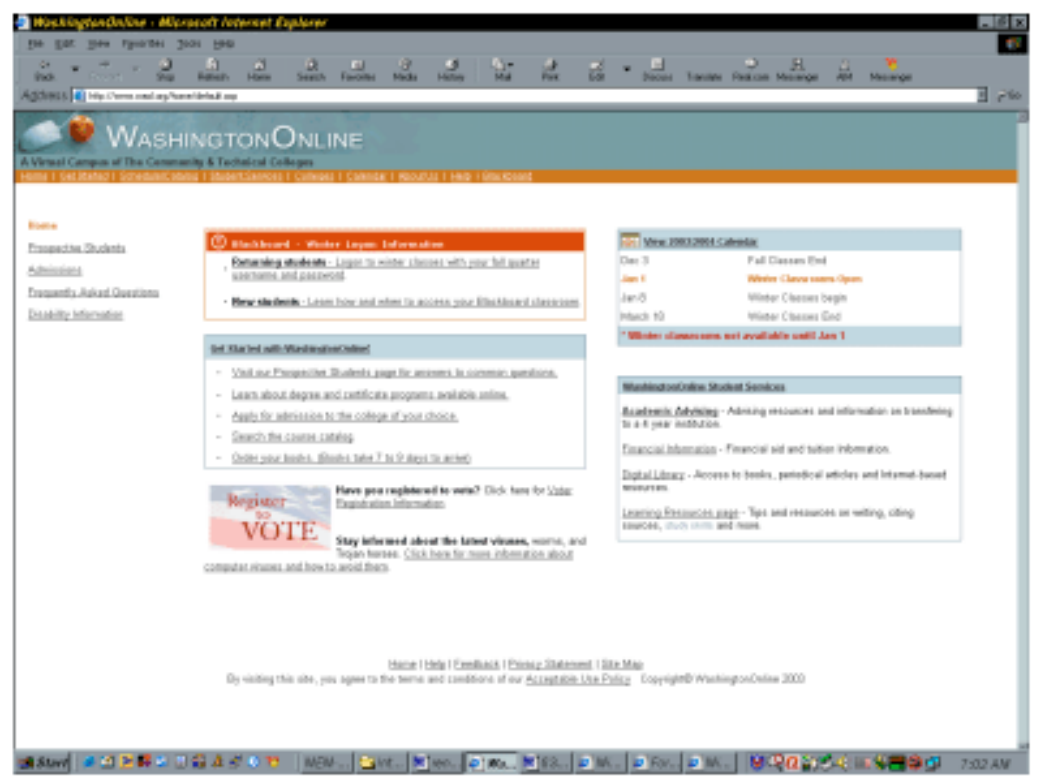

This research paper will examine WAOL's current organizational culture and how the WAOL leadership keeps the disparate parts of WAOL connected. This will also probe ways to strengthen this organization as it approaches its seven-year mark. This paper will propose some ideas on how to strengthen geographically-dispersed loosely coupled virtual higher education organizations.

\section{Research Questions and Approach}

Culture may be defined as "the sum total of all the shared, taken-for-granted assumptions that a group has learned throughout its history" (Schein, 1999, p. 29). Culture, while often unconscious, determines an organization's "strategy, goals, and modes of operating” (p. 14). This slice-of-life cultural analysis will examine how culture manifests in this loosely coupled organization. Emailed surveys of current administrators, staff and faculty were sent out in December 2003 and again in January 2004. These qualitative surveys asked for open-ended descriptions of WAOL's organizational culture in relation to its course design, technology decisions, policies, practices, and treatment of students - all major "flex" points of decisionmaking responsibility. How do administrators, instructors, and staff perceive how this current culture has come about? By design? Evolution? Happenstance? The survey also probed what respondents through comprised WAOL values; the brand or reputation of WAOL; the method(s) by which culture is communicated; how a sense of organizational cohesion is created; how quality standards for teaching are established; how decision-making is made (centralized, dispersed); areas for improvement in communicating culture, and the authorizing environment of the organization. (See the appendix for a complete copy of the survey.) In addition, artifacts such as policies and emails from WAOL were examined. Two emailed interviews were also done with Broughton, the Managing Director of WAOL. The results of the surveys were collated into a 
rubric, and the comments were analyzed for themes and recurrent ideas. Anomalies were also recorded and analyzed, in the context of researched information about WAOL. An assumed limitation of surveys involves its inability to address all relevant issues. Oftentimes, surveys address espoused values rather than hidden ones (Schein, 1999). Online surveys also have a tendency of low response rates (Watt,Simpson, McKillop, and Nunn, 2002).

\section{WAOL Organizational History: 1997 - Present}

A state-level ad hoc group met to consider the distance education options in Spring 1997. They debated whether to create a separate virtual college with its own accreditation (after the Western Governors University model) or to provide services through a distributed model. "This entailed creating a platform that an individual student could access in order to choose among a number of courses offered by various colleges. The student would remain enrolled at his or her home campus, but would be able to take a course offered by any other campus over the Internet” (Bleak and Chabotar, 1999, p. 3).

Moneys for the early years were piecemeal, with germination funds coming from the community and technical college presidents' respective budgets (interest from the Educational Technology Initiative). This starting amount would be US $\$ 530,000$ for the first two years. The money was managed by Spokane Falls Community College (SFCC), where WAOL would be housed. By the end of 1998, ONLINE had offered its first and second groups of courses. In January 1999, it offered its full first, second and third groups of courses, and redevelopment of its first term courses had begun by March 1999. The use of courses created by lead-instructors, overseen by fellow professors in the field, and taught by college instructors (with some minimal modification), set curricular standards for the Washington State branding. WAOL also allowed hosting of individual college-based courses (owned by the respective higher educational institutions) and the teaching of co-owned courses between WAOL and the colleges. The groundwork had been laid around coursework, technology, and collaborative faculty and administrators. An additional Fund for the Improvement of Postsecondary Education grant in 1999 further strengthened this fledgling organization. "Today, the grant is nearly over and all our budgets are for the first time in one place,” writes Broughton (Broughton, 2003a, n.p.).

\section{Authorizing Environment}

Various stakeholders influenced this upstart. As a complex organization linked to a large opensystems heterogeneous system of various community colleges, state-level agencies (the State Board for Community and Technical Colleges), and its micro-environment of SFCC, WAOL was highly dependent on its external environment for funding and college student enrollees. It not only had to self-manage, but coordinate public relations, educational course creation and delivery, technological innovations in courseware, and its identity within the higher education structure of Washington State. WAOL strategically grafted itself as a "shell" structure on the existing 34 State community and technical colleges. As the "WAOL About Us" part of the SBCTC site explains: "WAOL is not a college, so it does not directly register students, grant credit or determine grades. To register into a WAOL VC course, you need to enroll in a community or technical college that offers the course or courses you want to take. Once you are accepted as a student of the college, you can then register into the online course" ("WAOL About Us", Dec. 2003, p. 1). External survival issues include the use of a mission (strategy and goals), means (structure, systems, processes), and measurement (error-detection and correction systems), in levels of organizational culture (Schein, 1999). 
As a learning organization par excellence, WAOL used its sensing mechanisms to gauge the faculty and community-wide attitudes towards distance education. To anticipate fast-moving changes in a limited budgetary environment, it reached into private industry for understandings of Web-based courseware and changes in the field. It set state-wide policy for distance education the academic standards, the courseware technologies, the grading scale, and the employment of faculty. It created a syllabus and other form templates. It created an online training course for prospective online instructors. It built a semi-private Web presence for administrators and faculty and a public Web presence for adult learners. This organization identified relevant research on distance education - its methods, technologies, leadership practices, and policies - and integrated the learning into their own procedures. It soft-sold distance education to a skeptical faculty through state-level conferences and its mere existence, and it reached out to the public through mass media. It formed alliances with industries like The Boeing Company for mutually-beneficial collaborations and funding.

Accreditation of the partner community colleges, credentialing of the professors, their direct supervision in their respective work places, and the high standards of course creation and measurable course outcomes for each WAOL course, ensure the courses' legitimacy and academic and professional transferability. This approach saves moneys because there is no new physical plant, no capital-funded buildings. Rather, the structure built is in cyberspace and through political, business, and educational alliances. Much effort goes into the maintenances of such strategic alliances which are "fragile," but yet must be "strong enough to withstand a rapidly changing competitive landscape," notes Isabella (2002, p. 48). Successful alliances require collaboration, mutual compatibility, and the realization of the difficulty of achieving the shared aims alone (Dyer, Kale, and Singh. 2001). Figure 2 shows the complicated stakeholder issues in WAOL's authorizing environment.

Figure 2. WashingtonOriline Authorizitig Enwironment

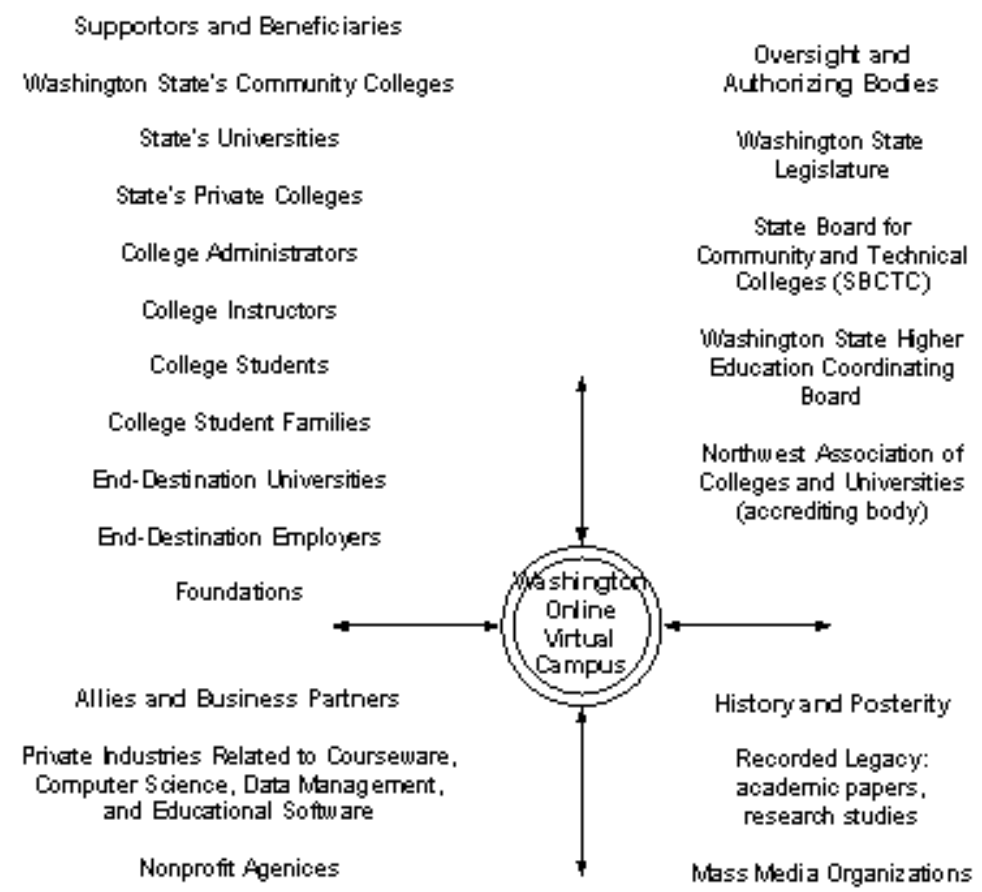




\section{WAOL as a Loosely Coupled Organization}

WAOL apparently fits Orton and Weick’s re-conceptualization of a loosely coupled educational organization in its fragmented external environment. Its wide number of external stakeholders adds a degree of "causal indeterminacy" to this organization (Orton and Weick, 1990). WAOLlinked institutions function as a combination of geographically-dispersed relatively autonomous independent units, which influence each other as modular building blocks. Different layers of administrative hierarchy also lead to greater dispersion of power. Relatively speaking, WAOL also fits this model because it is "relatively inexpensive to run, because it takes time and money to coordinate people” (Weick, 1976, p. 8). The task-induced tight coupling may mean ad hoc committees and temporary groupings within WAOL to achieve particular governance decisions, technological setups, exchanges of information or course development, but such tight couplings are transitory. Whether or not loose coupling is effective has been studied in various organizations, with mixed results. Raghunathan and Beekun (1989) concluded that in terms of strategy, loose coupling efficacy depends on a combination of environment and strategy (as cited by Orton and Weick, 2001).

Figure 3. Orton \& Weick's "Loose Coupling Theory Reconceptualized"

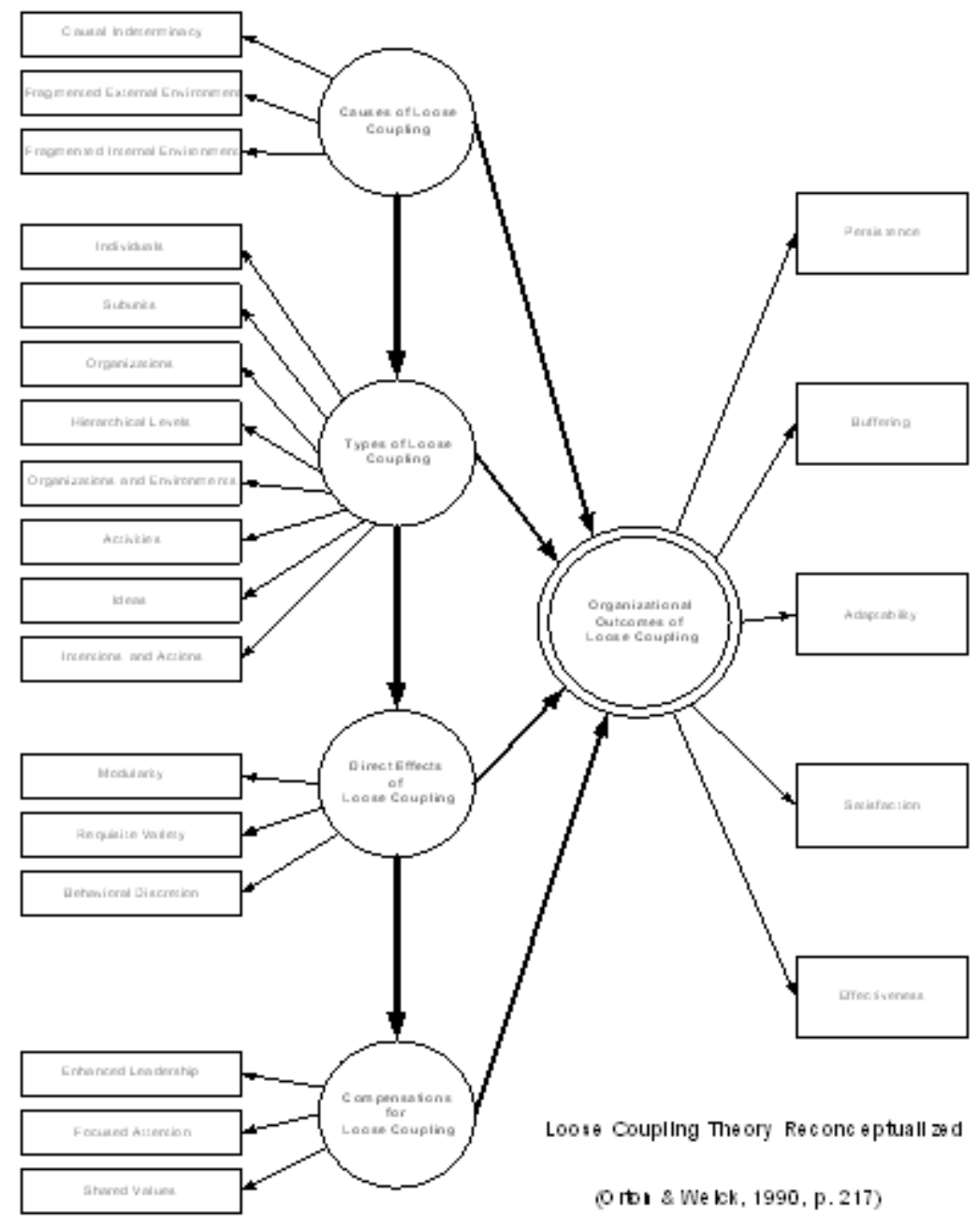


Frontline colleges and instructors have behavioral discretion in the educational approaches, albeit within the defined boundaries of the lead course setup. Courses have evolved in different ways on campuses, with requisite variety. The "organic evolved culture" applies to these various institutions based on the need for local adaptations and "mutations." Campus instructors practice self-determination about the curricular issues, based on the course curriculum set by the lead instructors (Orton and Weick, 1990, p. 217). Different campuses demonstrate varying subcultures and diverse levels of institutionalization of the DL model.

To maintain high academic quality, WAOL supports planned online and email interactions between learners and instructors in lieu of face-to-face socializing, in-class discourses, and classroom community cohesion. This aligns with best practices in the research literature: "An online course, properly crafted, builds in many opportunities for students to advance their learning through responses and discussions. Ideally, this interaction is neither haphazard nor left to serendipity, though spontaneity may figure in it" (Maeroff, 2003, p. 42). While some online courses require synchronous study - e.g., a set time when all learners would "meet" online in a shared MOO/ MUD (multi-user object oriented or multi-user domain space), with an instructor coordinating real-time discussions and calling on students electronically - the WAOL courses are asynchronous for convenience and flexibility. To address learning disabilities and preferences, the various courses entail a variety of teaching and learning approaches. Students are encouraged to reach out to instructors by email, phone, or in-person for support and direction. Electronic resources, simulations, downloadables, and lectures are available for student use throughout the quarter. Ongoing assessment through assignments, quizzes, and interactivity in classes strengthens academic rigor.

Loose coupling makes WAOL more adaptive and responsive to the needs of the Washington State's college system. Courses may be created and launched within a quarter. WAOL has sensitive sensing mechanisms regarding the external and internal environments - with its ties to state government in Olympia through the Washington State Board for Community and Technical Colleges (SBCTC) its distance learning coordinators on each campus, its faculty spread throughout the State, and its direct access to learners through email interchanges and surveys.

Job satisfaction may be another effect of loose coupling "because it affects efficacy, conflict, security, and social contacts." Specifically, the modularity of such organizations may encourage more frontline self-determination and sense of efficacy. Objectives may be set at the local level. Agreement on controversial issues may not be necessary between certain loosely coupled units. Also, a haven of psychological safety may exist where "deviance and experimentation" are protected (Meyerson and Martin, 1987, as cited by Orton and Weick, 2001, p. 215). The creation of smaller units of frontline instructors at a college may offer "increased task visibility, monitoring and social exchange among employees" (Orton and Weick, 2001, p. 215). Adaptability is yet another effect of loose coupling. This effect suggests that the organization may experiment more, share collective judgment and integrate dissent more effectively than organizations that are tightly coupled. In a loosely coupled organization, breakdowns may be isolated and kept from ripple effects throughout the organization through buffering.

Making changes through a loosely coupled organization, however, may be difficult. WAOL trains staff in each college, but staff turnover is constant, so training also must be continuous. Any change in process or policy must go through multiple organizational structures. The effects of the loose coupling may be observed as in a number of factors: persistence, buffering, adaptability, satisfaction and effectiveness (Orton and Weick, 1990). Persistence, defined as "stability, resistance to change, and continued operation," is seen as an outcome of loose coupling. Theorists 
argue that changes are easier to execute in tightly-coupled homogeneous organizations. WAOL, therefore, may have reduced responsiveness to centralized planning and change because of its loose organizational structure (Orton and Weick, 2001). For example, its attempts to unify DL on college campus has resulted in more dispersed individualized distance learning course offerings independent of WAOL.

WAOL works with and as state-level administration. The Advisory Committee directing WashingtonOnline Virtual Campus consists of members of various constituencies from DL administrators to industry personnel. Deans and department heads lie outside the direct hierarchical setup. Line instructors, including lead ones (who create original courses or who order books and do administrative work for particular clusters of courses, such as all English 101 courses), exist outside of this structure, too.

WAOL is a permeable organization, with a low cost of entry for instructors - once instructors have become part of the community college system. In other words, instructors must meet the hiring requirements for the community college system, with job descriptions listed with various human resources offices. Once an instructor is in, their competence is assumed, and the instructor becomes an atomized actor in relation to the learners via this system. To teach particular courses, instructors need to request a particular course, and the DL administrators on each campus would have to sign off on the assignment to keep the decision-making local. Entry for learners is also relatively low-cost, in terms of tuition and open-college entry standards (usually a pre-test with a range of pre-college and college-level score outcomes in math and English).

\section{Online Faculty Training}

WAOL created a four-week online training course for instructors desiring to teach through them. The curriculum addressed issues of WAOL policies, pedagogical approaches to online teaching, community building, online communications, and courseware technologies. This course also imbued incoming instructors with their cultural stamp - of high quality and student-centered services. This course is one major source of WAOL branding and culture-building. It socializes instructors into WAOL standards and practices. Here, the course builds a common language and shared concepts, creates a sense of WAOL identity, and defines the nature of authority and relationships. It also defines the allocation of rewards and status, all elements of Schein's internal integration issues in cultural layers of organizational development (Schein, 1999, p. 30). Organizational learning continues past the course - with frequent broadcast emails to instructors, an online shared space for collegial exchanges, annual representation at the SBCTC New Faculty Orientation in the Fall, and the occasional WAOL-sponsored conference.

This over-arching structure has meant that faculty would be hired through the campuses and supervised by the deans or department heads. While this simplified human resources management, that setup may have left a supervision gap for the instructors. Only in the situation of a student complaint would a campus's DL coordinator get involved. After all, on-campus personnel do not often lurk online or solicit student surveys from learners of WAOL online courses. WAOL itself does not have the staffing to provide such evaluations, and can not evaluate instructors directly because of contractual issues in this collective bargaining system. Instructors, who teach based on their higher education and experience, learn by doing. Then, many learn by doing or "intra-task learning," as is typified by those who work in virtual environments (Lindbeck and Snower, 2000). Statistically, faculty remain with WAOL for varying periods, but some have been with WAOL from its inception. Some have quit after a year or two, according to Broughton. 
Some teach "more or less according to other factors in their lives" (Broughton, 2004). One even has been teaching from out-of-state.

\section{Oz Effect Technologies}

Leadership exploits current technologies for the "Oz effect." Administrators maintain a listserv to communicate with instructors; they use this to notify them of deadlines, new technologies, and staff changes. Individual email accounts maintained by the staff also ensure their accessibility. Telecommunications is also used for more timely issues, such as grade queries. A toll-free telephone number helps core staff connect with all their constituents. A faculty section on the WAOL website offers an easy way to exchange digital information and files. The richness of interactive communications technologies allows for a number of connection points for WAOL instructors. WAOL's "tele-presence" coalesces around its information provided by its website and the listserv messages. The various connections are formal, but staff members maintain a colloquial tone and timeliness in responses that welcome communication. These professional relationships are typified by trust. "When we do not trust the competence of people, we supervise them. Traditional organization hierarchies suggest cascading rungs of police and inspectors. When people's jobs occur in different functions, we coordinate them . . . These presumptions of incompetence are the roots of towering hierarchy, functional isolationism, and overspecialization” (Whitney, 1994, p. 127). Research on virtual universities suggests that tight coupling is an important pre-requisite for control and governance (Guri-Rosenblit, 1999, p. 172).

\section{WAOL Culture: Survey results}

Leaders embed cultural elements through primary and secondary means. Primary embedding mechanisms involve what leaders "pay attention to, measure, and control regularly," how they react to critical incidents, observed criteria for scarce resource allocation; deliberate role modeling and coaching; the distribution of rewards, and the "observed criteria by which leaders recruit, select, promote, retire, and excommunicate organizational members.” Secondary "articulation and reinforcement mechanisms" may involve structural elements: "organizational design and structure; organizational systems and procedures; organizational rites and rituals; design of physical space, facades, and buildings; stories, legends, and myths about people and events; formal statements of organizational philosophy, values, and creed” (Schein, 1999, p. 98). How has WAOL evolved? Three administrators, 21 instructors and two staff members responded to the emailed survey. The following provides an overview of the survey results, with a special focus on lessons learned that may be useful for other similar "virtual" organizations.

\section{Administration}

One outstanding aspect of the administration was their view of themselves as the middle-person between various entities. Two of the responses observe that WAOL only has a limited role in course development, contingent on funding. WAOL strives to be "supportive of helping find ways to make good ideas happen." Technology decisions are seen to be "at the mercy of vendors and CTC (community and technical colleges) system resources," as well as student accessibility. WAOL administrators find themselves caught between various stakeholders. One respondent described policy-making as "trying to balance the needs for order/ structure/ consistency to expedite services for all in the CTC system against limited resources and many competing interest/ viewpoints.” 
Personality clashes unduly affect such organizations, particularly if the decision-making is "fairly closed and directive.” Operational decision-making falls to the responsible staff member, but nonoperational ones apparently are made by higher administration - which is perceived as not fully connected with frontline management and staff concerns. Another suggests that major decisions are made by a core team within WAOL. Other times, a more public process is followed via "system councils and commissions to get as much feedback and buy-in from colleges as possible." Major decisions regarding policy are addressed by the Washington Association of Community and Technical Colleges (WACTC) WAOL Executive Board, often with approval by the appropriate commission (Instruction, Student Services, or both). As one notes: "The matrix is as complex as are the relationships to the many constituents in the CTC system.”

\section{Participative Leadership}

One administrator describes the necessary dynamics of a consortium to have every stakeholder feel involved in every decision, given the highly public environment. The stakeholders may be perceived to be the students, but also involve the State's 34 community colleges and the State's college's presidents and legislators. With so many competing interests, it may be difficult to show a "strong cohesive image with clear goals," writes one administrator.

The organization's culture evoked a broad divergence of opinions. One suggested that the culture is a mixture of all three factors (design, evolution and happenstance) as well as the personalities of those involved. Another suggested that the decisions of the original Steering Committee have remained unchanged through these years, so this respondent opted for "deliberate design." Another suggested that evolution plays a role because of gaps in leadership, and happenstance because "we all work independently and don't have much direct supervision so that has created a fairly loose structure."

The administrators unanimously agree that WAOL uses a service-oriented model to sustain student-centered learning. One emphasizes the "single-point contact" approach: "WAOL's goal is to provide access to students in a way that is easy to figure out, always available, and of high quality. Another named "inclusiveness, responsiveness, innovation, accountability . . . Because WAOL is sort of an 'outsider' (not affiliated with any college), we have to maintain good relationships with all the colleges and need to be perceived as being flexible and accommodating of colleges' needs.”

\section{Brand Under Radar}

The brand "penetration" into the larger awareness seems low. "I think the brand is little recognized outside the current college staff who engage with the WAOL endeavor and the students who are taking classes. Most community members who are not attending classes remain unaware of its existence. For those who have taken classes, taught, or administer DL programs, the reputation is that WAOL does a difficult job well.”

\section{Electronic Acculturation}

Communications with frontline instructors seem based around email conversations and the acculturation through the four-week training program. Lessons from the culture are reinforced through interactions. "All instructors are required to take a completely online training course that uses the WAOL instructional design model. When instructors contact our office, we try to 
'remind' them of the rules we live by, for instance, that classes are supposed to be interactive, etc. The internal WAOL site http://www.waol.org/info has a lot of information about the WAOL standards and culture as well. WAOL encourages instructors and college staff to use this site. WAOL instruction staff has periodic meetings where we talk about what is working and what isn't. We brainstorm solutions to problems. I think it is very important that we stay open all the time to new ideas and to the possibility that we really can figure out a way to fix everything."

\section{Electronic Connectivity in Question?}

While its website is informative, a recent survey by WAOL found that "most users are not spending much time on our website. We need to work on that or figure out another way to communicate to our users.” In other words, the opt-in piece needs to be stronger for this high-tech distributive model to work fully. Even at the college level, many do not understand WAOL in the way administrators would like - as trying to "help colleges serve their students better. I think some college staff see WAOL as a competitor." This administrator continues: "I also think some college staff and some students think WAOL has more power than it does."

\section{Low Culture of Sharing Courses}

The concept of sharing courses has worked only for some. This administrator writes: "We need to figure out how to share courses among colleges better. This job will require both a cultural shift and possibly a different cost model.”

WAOL has struggled to promote a sense of cohesion given its disparate physical locations. One administrator described weekly phone meetings which are effective for "specific, shared task(s)." They have also tried face-to-face meetings, which are less successful because of their brevity and the hindrance of travel. One writes: "At one point, we figured out that we were trying to work too much in a hierarchy and decided that we should just call each other more often. For instance, if you get an email and are not sure what the other person wants, just pick up the phone instead of getting mired down in emails that are being misunderstood. If you need something, don't go up the chain and hope that your request goes back down to the right person. Instead, just call (or email) the person you need help from.”

\section{Faculty}

Twenty-one faculty members of the 350 currently teaching for WAOL responded to the survey or six percent. One faculty suggested that the lack of instructional support and guidance after the initial four-week WAOL course caused hardships. "There is a great deal of freedom; however, there was also a lack of support and guidance. The two don't always work best, especially when starting into a new way of learning. In my experience, faculty were to receive assistance from their peers regarding curriculum development; however, the course design consisted of one online class. In retrospect, I think having a series of short courses would have been helpful.”

Faculty do not perceive much power regarding the choice of courseware technologies, with a number responding that they do not have "any input" on changes to the course platform. A majority said they were not familiar with the administrative decision-making that went into the selection of courseware. Several mentioned the need to be forewarned of upgrades to the software earlier. One anomalous response suggests a line-level of power and decision-making: "I have been able to make all of the technology decisions with my technical advisor from my college and 
this has proven to be an outstanding experience.” Others express a non-interest in the decisionmaking regarding technologies.

\section{Course Stasis}

One faculty member expressed frustration at the inflexibility of changing some content: "I am a seasoned instructor and am not impressed with the lack of changes in the course content over time. I am appalled by the use of the same discussion questions and virtually the same test questions quarter after quarter." Some faculty members noted that instructors are "free to customize the course as we want within a certain framework" or to "tweak" the courses as needed. Another observed that the courses tend to be "traditional" versus "dynamic or avantgarde.”

\section{Policies on the Front Lines}

A number of respondents were apparently unaware of WAOL policies. One decried the administration for focusing less on education than on a commodity. "The administrators are not all educators. That is a mistake. Many of the policies are not informed by education needs. At times has the fill of a product/ commodity-driven policy format.” Others expressed their own non-participation, but satisfaction nonetheless: "Clear enough, flexible, in process and getting better." Another described WAOL policies as "open, instructive and fair." Specific policies were criticized. The limited grade spread (an " $\mathrm{A}$ " is a 4.0 instead of a range from 3.5 to 4.0), the disallowance of unregistered students to access the Blackboard site before the second week of the quarter, precipitous technology changes without sufficient instructor preparation (e.g., switch to Web submission of grades, registration for course assignments, upgrading of courseware), and the lack of student emails for some accounts, were all concerns.

Faculty expressed concern at the lack of student awareness of WAOL, while acknowledging its popularity. Some learners do not realize their instructor for their courses would not necessarily be on the learners' own respective campus. They observed that each of the colleges have different levels of service for learners. Faculty perceive WAOL's culture as a product of both evolution and happenstance. One sees WAOL as a result of "the needs of part-timers to eat" as well as a welcoming of "younger persons more likely to know the technology and more likely to be hungry enough to invest in the level of amount of work that is needed to develop a course." Others see turf wars as causal agents in WAOL's current culture: "We knew we needed to get into online, but turf wars are a hassle with colleges and WAOL and some other tri-college organization in the State fighting it all out for the students and the bucks.” Some cited the organization's integrity and push for student access to "equal education." Some who say they are not aware of WAOL values, express a correlating apathy regarding the culture. "Don't know, don't care. It's my course and my values in teaching it that matter to me." The question on WAOL brand engendered quite a bit of confusion. "Low contact, market driven," one writes. Another lists "reputable and pioneering," "tight and efficient," and "positive."

A majority of instructors said that they "never talk" to any WAOL instructors who are not in their own discipline; rather, they discuss issues with their own campus peers. Several suggest that improved communications - through a listserv or e-newsletter - would be useful for two-way communications, instead of the one-way broadcast emails. Not surprisingly, faculty members describe "significant isolation associated with this form of teaching." While some know other online instructors, they do not feel WAOL particularly fosters such interrelationships. Many connect tenuously through "regular emails, but I think a sense of cohesion is lacking. We all teach 
for our own campuses and have little if any link with each other.” Approximately 50 percent of respondents advocated greater cohesion, while the others expressed their lack of desire for greater cohesion.

Instructors highlighted various ways that they establish quality standards: customizing courses, being accessible, staying on top of technological glitches, soliciting student feedback, setting high standards and expectations for student behaviors (particularly being respectful, responsible and fully prepared for the assignments), staying on top of developments in respective fields, making standards of instructor-student interactions explicit from the beginning, and providing individualized attention and help. Others want more feedback and peer exchanges regarding their teaching. "I would like to know how other teachers handle problems, records, new ideas ... An online newsletter telling us what's up at WAOL and some new "tips" each term/ month would be great!”

Only one respondent seemed to have had direct decision-making input (in drafting WAOL guidelines) but felt rebuffed. "Although it seemed like they were asking for input, there seemed like there was already a direction in which they wanted to head." Even lead instructors seem to eschew participative decision-making: "Major WAOL decisions regarding curriculum and instruction appear to be made and executed centrally, including assigning instructors to classes." Yet another described never being asked for feedback on any decision. This respondent continues: "The decisions just sort of appear to drop out of nowhere via email. Some say that decision-making within WAOL is "dictatorial," with an overemphasis on "teaching efficiency."

\section{Staff}

Two staff members highlight the limitations to WAOL's power as a consortial organization. "WAOL as an entity set up the initial requirements for course design, and had a peer group for each developing course review the curriculum to make sure it was appropriate. WAOL can suggest design features, but cannot enforce adherence. WAOL provides the technology for the courses, but cannot develop or affect curriculum," reads on response. Another mentions financial constraints.

Policymaking apparently hails back to the original founding vision. Staff see strong adherence to stated policies. "WAOL staff strives to practice what it preaches. A great deal of communication is sent to colleges and faculty to make sure participants are aware of how to use WAOL to their best advantage." Changes in policies are affected by more than just staff or management desires." Another expresses a sense of frustration with changes in WAOL's structure with its integration into the SBCTC, with more human involvement and a lack of understanding by "very upper management."

Echoing the findings from administrators and faculty, the staff expressed positive observations about service to students. "No student request is discounted, and we always try to solve a problem before it escalates, or forward it to the person who is authorized to deal with it," writes one staff respondent. Another writes: “Excellent treatment of students!" and highlights WAOL's professionalism and timeliness. Staff members express awareness that every email, telephone, or one-on-one communication carries some of its culture forward.

Staff respondents emphasize student feedback for checking quality standards. Some colleges apply more oversight in surveying students who take online courses. Problems with instructors are relayed to the respective colleges for their management. Instructors with repeated "issues" are 
brought to the attention of the hiring colleges. According to staff, quality is maintained by listening to its various constituents. "WAOL-related services also rely on feedback from DLC's (distance learning councils), faculty and students. Problems are resolved as soon as possible, with corrections made so they do not recur. Staff monitors services vendors to make sure they are meeting our expectations, and steps in to correct any shortcomings." While staff observes cohesion at their direct work levels, one observed a lack of cohesion at the higher levels of management. One observes that some standards-setting may be contravened by union intervention. Both staff respondents suggest that decisions are made in a centralized way after much information-gathering and consensus building. One notes that not all staff feedback or recommendations were followed.

WAOL makes decisions with forethought: "All changes have to be weighed carefully because not just one entity is affected. The challenge is trying to decide which changes are necessary, then how to best time, communicate, and implement any change to a greatly diversified group. The bottom line stakeholder is the student body. How they are affected depends on what change needs to be made.” Staff members see distance learning coordinators as key contacts in communicating changes to WAOL faculty, support staff at the college levels, and students.

\section{Analysis}

\section{Adding Value}

Competition has sprung up with WAOL for the offering of homegrown college-created online courses delivered off their own servers, with their own individual contracts, with courseware providers like Blackboard. With the budget crunches of the early 2000s, these partnerships have been under pressure. Many institutions have built their own former-fledgling distance education offerings, and many are balking at paying WAOL fees, so there have been withdrawals of offerings of WAOL courses. Some colleges are now only offering WAOL courses where their own faculty members are unable to provide a particular course, in order to lower chances of competition for full-time equivalences (FTEs).

WAOL needs to fight the disintermediation of its consortium members by offering additional value through new services or additional alliances. Broughton suggests that WAOL may work with four-year colleges to offer value to the community and technical colleges and students. "I think we probably will in the next year, and if we do, I think we will make certain that the partnership benefits community and technical colleges and their students, and that the partnership is one that could be offered to other colleges as well.” says Broughton (C. Broughton, 2003c, p. 2 ). Broughton believes that colleges stay connected with WAOL, because the cost to belong is low at US $\$ 6,500$ per year and because it offers value. WAOL also offers a comprehensive course listing for the colleges at no direct cost to the institutions. It offers technical backend that is easier for colleges to use. With over a million hits a month, the website adds value (Broughton, 2003b).

\section{Transforming Culture through Internal Sharing of Expertise}

WAOL could strengthen its position by creating a "collective mind" of shared knowledge among its dispersed members, who share a "cognitive interdependence" (Yoo, 2001). Failure to exchange information in a useful manner, may blunt a "team's capacity to learn" (Cramton, 2002). It needs to capitalize on line-staff expertise and insights for some of its changes. Researchers suggest the benefits of the "collegium" among "people who have equal influence, 
equal information, and a decision scheme of majority rule are able to apply multiple perspectives to situations and combine their perspectives to create a collective judgment. Because of the relative advantages of the loosely coupled form in creating collective judgment, it is not surprising that collegium forms . . . are heavily represented in loose coupling literature” (Orton and Weick, 2001, p. 214). Dissent must be preserved for loosely coupled organizations to survive, something called "unified diversity” by Eisenberg (1984) (as cited by Orton and Weick, 2001). Dissent may lead to improved adaptability, creativity and survival (Orton and Weick, 2001). WAOL employs quarterly student surveys, email communications with faculty and DL administrations, frequent telephone communications, and real-time responses for error-detection.

\section{E-leadership Needed}

Weick's (1993) concept of “theatrical improvisation" as a metaphor for organizational change suggests that it occurs from "ongoing, unplanned, and situated adaptations of organizational members in their everyday work life.” Building on this, Orlikowski (1996) suggests that such changes may be "shared, amplified, and sustained" for long-term organizational change (as cited by Avolio, 2000). Applied in the context of e-leadership, as is the case for WAOL's hybrid leadership, Avolio's Adaptive Structuration Theory suggests the need for leaders (administration and faculty) to create social and knowledge structures that are accessible and effective "to produce a change in attitudes, feelings, thinking, behavior, and/ or performance with individuals, groups, and/ or organizations. E-leadership can occur at any hierarchical level in an organization. It may be associated with one individual, or shared by several individuals as its locus changes over time" (Avolio, 2000, p. 616). This theorist cites a study by Kahai and colleagues that showed that "group members were more supportive of each other using a groupware system designed to enhance collaborative interaction when the leader was more participative versus directive" (as cited by Avolio, 2000, p. 621). There are risks to introducing new technologies to a group, so such changes should be actualized with care (Avolio, 2000).

\section{Clan Orientation}

Orton and Weick (2001) suggest that tight cultural couplings or "clan orientation" through shared values and communications - are critical in holding a loosely coupled organization together (p. 213). This organization's culture seems to be dominant on some key points: ease of access, professional and timely staff responses, and support of learners and instructors. Beyond a few core values, however, much disparity apparently exists depending on the various lead instructors and other faculty for courses and different colleges' leadership and support for DL. The organization's continuance of its name WAOL for the Virtual Campus shows that its geographical and academic branding "trademark" value is to be protected. Brand value in online programs is critical. Goldberg and Seldin note that regional institutions will now face "an overwhelmingly crowded competitive scene" from national and even international levels (Goldberg and Seldin, 2000, p. 300). WAOL assiduously protects its reputation. As a non-profit state-funded organization, WAOL has stayed close to its roots as a non-commercial entity, with no sales of student email lists, no advertising. "We are seeing the emergence of a new type of organization that undermines the familiarity needed to sustain trust. New information technologies are resulting in what some call a 'virtual organization,' where personal contact among employees is transitory or even non-existent. People are being asked to trust others whom they know little or not at all. They are being asked to make themselves more vulnerable to others than ever before" (Shaw, 1997, p. xiv). WAOL has long-standing links to the community which enhances its level of mutual trust, but more work may also be done in this area. 


\section{Requisite Course Variety}

Building on a history of locally-developed courses, this organization may broaden its course offerings. While the learning is "anytime, anywhere," it is not also "any path, any pace." The pegging of the WAOL quarter to that generally of the various community colleges of the state influenced the 10-week quarter schedule of WAOL, because of instructors' need to submit grades by certain deadlines for colleges through WAOL's administrative offices. WAOL may support the development of courses that are co-taught by instructors at different schools; courses that combine for interdisciplinary studies; course that create virtual communities with others abroad; courses that involve a travel component; hybrid varieties or a number of other permutations. An online or email-based tutorial service may be made available to learners.

Broughton identifies WAOL culture as "collaborative, consortial, experimental, (and) mellow" (C. Broughton, 2003c, p. 1). According to the research literature on loosely coupled systems, leadership usually manifests as "strong” or "subtle." WAOL apparently follows the latter course, described by Boynton and Zmud (1987) as "to simultaneously provide centralized direction and coordination, while recognizing the value of increased discretion.” (Orton and Weick, 2001, p. 212) Weick himself advises that educational administrators pay more attention to the "glue" that maintains loosely coupled systems: "Since channels are unpredictable, administrators must get out of the office and spend lots of time one on one - both to remind people of central visions and to assist them in applying these visions to their own activities." (Orton and Weick, 2001, p. 212) Research on loosely coupled organizations would suggest that more "focused attention" on the various relationships and "small step strategies" on carefully selected targets within the system would be useful in enhancing the organization (Orton and Weick, 2001). The growing popularity of e-books and online libraries may well strengthen WAOL's delivery of digital course materials. How ready is WAOL Virtual Campus to broaden its mandate, and can it bring its allies and detractors along with its virtual future?

\section{Application to Other Settings}

One may argue that a "virtual" leader of a loosely coupled virtual higher education organization needs to promote a coherent culture in order to unify the widely disparate elements of a geographically-dispersed organization. The "shimmer" between self-identity as stand-alone units and team identity as part of the whole may be disruptive to the larger organization's coherent identity. Feelings of disconnection by line faculty and staff, and misperceptions about intentions behind administrative decisions may threaten a decentralized organization's functions. Engaging the far-flung elements of a loosely coupled organization into the heart of decision-making through participative leadership may be one hedge against disconnection.

Ways to build cohesion include the consistent interchange of information among the members of the group. This information should be made available among the various constituent members in an open exchange to avoid information siloing, whether this compartmentalization of information comes from geographical, cultural, departmental, field, language, college, or other divides. Addressing such pooling of information resources will require planning and continuing support.

Another important virtual leadership element would be the ability to transition the organization to face evolving external realities and competition. To keep the organization intact through the needed changes, the constituent members will need to be heard and their concerns addressed; the diversity of ideas needs to be encouraged through respectful communications and openness. The early-state attentiveness to its constituents through sensing mechanisms is important to maintain 
for a holistic 360-degree perspective. Particular attention should be paid to schisms between different internal constituents, simply represented here as administration, faculty and staff. "Virtual" leaders should demonstrate leadership through clear communications - through messages, policies, and consistent embodied/ practiced actions - to maintain a sense of institution focus and unity. An active and continuing public relations push for brand penetration may also promote the organization and its service to a wide range of stakeholders.

Strategic alliances which are mutually rewarding should be maintained, and those that no longer support the consortium should be discontinued. An evaluation of these partnerships should be established not based on past practices per se but on current benefits and future potentialities. New consortium partners that may bring benefits to the learners should be brought on, even if that involves a change in mandate or temporary discomfort as changes are made to reorganize the "modules." Fresh constituencies may be served, and with their integration, other changes may be made to the structure. Savvy leaders must pay attention to organizational needs for change based on other adjustments. From the loose coupling perspective, leaders need to identify the parts of the organization that need tightening, those that need loosening and those elements that need to be disconnected altogether.

\section{References}

Avolio, B. J. (2000). e-Leadership: Implications for theory, research and practice. Leadership Quarterly, 11(4), 615 - 669.

Bleak, J., and Chabotar, K. J. (1999). Washington ONLINE (A) and Washington ONLINE (B).. President and Fellows of Harvard College. Cambridge, MA.: Programs in Professional Education at the Harvard Graduate School of Education.

Broughton, C. (2003a). Query re: budget. Email correspondence with author. July.

Broughton, C. (2003b). Early draft. Email correspondence with author. August.

Broughton, C. (2003c). Personal interview with Connie Broughton. December.

Broughton, C. (2004). Very early draft. Email correspondence with author. February.

Carlson, S. (2003). Email correspondence with author. July.

Completely online certificate and degree programs. (2003). WashingtonOnline (WAOL). Retrieved July 3, 2003 from: http://www.waol.org/coursecatalog/collegeProgramsList.asp

Cramton, C. D. (2002). Finding common ground in dispersed collaboration. Organizational Dynamics 30(4), 356 - 367.

U.S. Department of Education (1998). Distance education in higher education institutions: Incidence, audiences, and plans to expand. (1998). U.S. Department of Education: Office of Educational Research and Improvement. National Center for Educational Statistics. Issue Brief: $1-2$. 
Dyer, J. H., Kale, P., and Singh, H. (2001). How to make strategic alliances work: Developing a dedicated alliance function is key to building the expertise needed for competitive advantage. MIT Sloan Management Review 42(4). 37 - 43.

Goldberg, E. D., and Seldin, D. M. (2000). The future of higher Education in an Internet world: twilight or dawn? In M. J. Finkelstein, C. Frances, F. I. Jewett, and B. W. Scholz (Eds.) Dollars, Distance, and Online Education: The New Economies of College Teaching and Learning. (p. 296-313) Series on Higher Education. The American Council on Education and The Oryx Press. Phoenix, AZ.: The Oryx Press.

Guri-Rosenblit, S. (1999.) Distance and Campus Universities: A comparative study of five countries. New York: Pergamon Press.

History and Mission. (2003). WashingtonOnline (WAOL) website. Retrieved July 3, 2003 from: http://www.waol.org/aboutUs/historyMission.asp

Isabella, L. A. (2002). Managing an alliance is nothing like business as usual. Organizational Dynamics, 31(1). 47 - 59.

Lindbeck, A., and Snower, D. J. (2000). Multitask Learning and the Reorganization of Work: From Tayloristic to holistic organization. Journal of Labor Economics, 18(3), 353 - 376.

Maeroff, G. I. (2003). A Classroom of One. New York: Palgrave MacMillan.

Orton, J. D., and Weick, K. E. (1990/2001). Loosely Coupled Systems: A reconceptualization. Anatomy of Management Review, 15(2), 203 - 223.

Schein, E. H. (1999). The corporate culture survival guide. San Francisco: Jossey-Bass.

Shaw, R. B. (1997). Trust in the balance: Building successful organizations on results, integrity, and concern. San Francisco: Jossey-Bass.

WAOL About Us. (2003). WashingtonOnline (WAOL) website. Retrieved December, 2003 from: http://www.sbctc.ctc.edu/dl/waol.asp

Watt, S., Simpson, C., McKillop, C., and Nunn, V. (2002). Electronic Course Surveys: Does automating feedback and reporting give better results? Assessment \& Evaluation in Higher Education 27(4), 325 - 337.

Weick, K. E. (1976). Educational organizations as loosely coupled systems. Administrative Science Quarterly, 21(1), 1 - 19.

Whitney, J. O. (1994). The Trust Factor: Liberating profits \& restoring corporate vitality. New York: McGraw-Hill.

Yoo, Y. (2001). Developments of transactive memory systems and collective mind in virtual teams. The International Journal of Organizational Analysis, 9(2), 187 - 208. 
Zigurs, I. (2003). Leadership in Virtual Teams: Oxymoron or opportunity? Organizational Dynamics,31(4), 339 - 351.

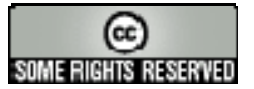

